\title{
Breast Cancer Patients' Experience and Wishes Regarding Communication on Sexual Health - The BEROSE Study
}

Marion Aupomerol ( $\square$ marion.aupomerol@gustaveroussy.fr )

Gustave Roussy Institute: Gustave Roussy https://orcid.org/0000-0001-5339-4507

Dan Chaltiel

Gustave Roussy Institute: Gustave Roussy

Patricia Pautier

Gustave Roussy Institute: Gustave Roussy

Delphine Wehrer

Gustave Roussy Institute: Gustave Roussy

Lucie Véron

Gustave Roussy Institute: Gustave Roussy

\section{Léna Degousée}

Gustave Roussy Institute: Gustave Roussy

\section{Leonor Fasse}

Gustave Roussy Institute: Gustave Roussy

\section{Laure Guéroult Accolas}

Gustave Roussy Institute: Gustave Roussy

\section{Antonio Di Meglio}

Gustave Roussy Institute: Gustave Roussy

Florian Scotte

Gustave Roussy Institute: Gustave Roussy

\section{Anne De Jesus}

Gustave Roussy Institute: Gustave Roussy

Inès Vaz Luis

Gustave Roussy Institute: Gustave Roussy

\section{Suzette Delaloge}

Gustave Roussy Institute: Gustave Roussy

\section{Barbara Pistilli}

Gustave Roussy Institute: Gustave Roussy 
Keywords: Communication, Sexual Health, Breast Cancer, Survey.

Posted Date: July 13th, 2021

DOI: https://doi.org/10.21203/rs.3.rs-427074/v2

License: (c) (1) This work is licensed under a Creative Commons Attribution 4.0 International License. Read Full License 


\section{Abstract}

Purpose: Although sexual health $(\mathrm{SH})$ is a major concern for many patients with breast cancer (BC), only few of them receive adequate information on this topic throughout their whole care pathway. BEROSE is a single-center pilot cross-sectional observational study, which aimed at evaluating communication on $\mathrm{SH}$ between women with $\mathrm{BC}$ and their health-care providers.

Methods: From June 12th to July 31st, 2020, a survey was distributed to patients consulting at Breast Cancer Unit of Gustave Roussy Cancer Center. The primary endpoint was the rate of women reporting to have received information on $\mathrm{SH}$ from health professionals throughout active treatment administration or BC follow-up.

Results: Of 348 surveys collected, 318 were fully completed and included in the analysis. Sixty-one percent of women were older than 50 years and $65 \%$ had a localized BC. The majority (63\%) was receiving hormone-therapy (37\%) or chemotherapy (26\%). Overall, $65 \%$ reported that they had not received any information about SH throughout their care, while $69 \%$ felt it would have been important to discuss sexual issues. For $31 \%$ of women, professionals, preferably oncologists or gynecologists, should have initiated the discussion on $\mathrm{SH}$, during an in-person consultation. Concerning satisfaction on $\mathrm{SH}, 83 \%$ reported being satisfied or very satisfied before BC diagnosis, and only $30 \%$ at the time they completed the survey.

Conclusion: Most of women undergoing treatment or follow-up for BC feel that they lack of adequate information regarding sexual issues associated to $\mathrm{BC}$. The impact of $\mathrm{BC}$ diagnosis and treatment on $\mathrm{SH}$ should be discussed with all women from the first visit and then regularly readdressed.

\section{Introduction}

Breast cancer (BC) represents the most common cancer in women in the world [1]. Thanks to improved screening programs and systemic and locoregional treatments, the mortality from $\mathrm{BC}$ in Western countries is steadily decreasing. Patients with metastatic $B C$ are living longer, by virtue of more effective systemic therapies [2,3]. Thus, it has been estimated that two million women in Europe currently have a $\mathrm{BC}$ history [4]. Maintaining a long-term quality of life is therefore a major health concern among women that are being treated for early and advanced BC [5].

In this context, several studies have evaluated the impact of BC on women's sexual health (SH), with 34 to $85 \%$ of women reporting sexual problems during and / or after BC treatment [6-8]. Multiple factors and treatment side effects may directly or indirectly affect $\mathrm{SH}$. Body image modification induced by local and systemic therapies, along with weight gain and fertility impairment associated to chemotherapy and endocrine therapy can severely undermine self-confidence $[9,10]$, especially among young women $[11$, 12]. In addition, fatigue, pain, vaginal dryness, decreased desire and hot flushes that tend to persist for long time after treatment termination can hinder the recovery of sexual well-being [13-15]. Finally, the psycho-social burden deriving from the diagnosis of $\mathrm{BC}$ and treatment side effects, including fear of 
being sexually unattractive following body changes, fear of cancer recurrence and death, changes in social and work position $[16,17]$ and changes in the couple dynamics [18-21] are major obstacles to a normal SH [22-24].

So far, the issue of sexuality in women with $B C$ is often under-addressed $[22,25,26]$ although prior studies showed that $68 \%$ of women with BC experience sexual difficulties and $60 \%$ sought to receive information on BC-related sexual changes, regardless the stage of the disease [27] even in advanced cancer or palliative care $[28,29]$. Women often do not raise the question as the decline in the quality of sexual life is perceived as a "price to pay" [30] or they do not feel comfortable to discuss sexual concerns with their healthcare providers and would prefer the professionals to initiate the discussion on $\mathrm{SH}$. [31, 32]. However, it is also difficult for healthcare professionals, to address the topic of SH due to lack of adequate training [33], lack of time [34, 35], or embarrassment [36].

Health-care providers thus play a key role in providing timely information on the sexual consequences of $\mathrm{BC}$ diagnosis and treatment and advising women and their partners on the possible solutions.

Nevertheless, few studies evaluated patients' perceptions regarding communication on $\mathrm{SH}$ with health care providers, at different time points of BC care and follow-up. We therefore conducted a crosssectional study, among women with all stages of $\mathrm{BC}$ from a single large comprehensive cancer center, with the aims of determining the rate of women who received $\mathrm{SH}$ information from health professionals, describing the characteristics of such communication and assessing patient's satisfaction with the information received.

\section{Methods}

\section{DESIGN AND SETTING}

The BEROSE study (Breast cancEr patients' expeRience with cOmmunication on Sexual hEalth) is a crosssectional observational pilot study carried out at Gustave Roussy Cancer Center (GRCC), a comprehensive cancer center located in a large urban area (Villejuif, France).

\section{PARTICIPANTS}

From June 12 th to July 31 th, 2020, all women $\geq 18$ years old, with any stage of breast cancer, who had an in-person visit or a teleconsultation in the Breast Cancer Unit at GRCC and were undergoing standard follow-up or receiving anticancer therapy for early or metastatic BC, were asked to fill in a one-time survey. Women were considered ineligible if they had severe cognitive or psychiatric illness or if they were unable to read and/or write French language.

\section{PROCEDURES}

Participants who came to GRCC for an in-person visit could choose between a paper or digital survey. The latter was administered using a SurveyMonkey link (http://www.SurveyMonkey.com), accessible through a QRcode. Women who had teleconsultations received an email containing the link and the 
corresponding QRcode. Women who had multiple consultations during the study period were invited to fill in the survey only once. The questionnaire was completely anonymous and no personal information was collected from participants. Neither reminders nor second invitations were sent to any of the participants. The survey did not allow to identify the person even indirectly, accordingly to the French legislation [Jarde's law, November 2016] and the EU General Data Protection Rules. As such, the study was approved by the Institutional Review Board (IRB) on April 28th, 2020 and was internally validated by the data protection officer. Because the law establishes that for risk-free researches informing the patient of their right to oppose to the use of their data is sufficient, no written informed consent was required from participants. The first page of the questionnaire contained a letter informing patients that by completing the questionnaire, they gave their consent to participate in the study and included a box to be checked in case of refusal to participate.

\section{QUESTIONNAIRE}

Since there did not exist validated questionnaires evaluating communication between patients and health-care professionals about SH in women with BC; we created an ad hoc questionnaire, building on published studies about $\mathrm{SH}$. The questionnaire was reviewed and validated by a panel of diverse healthcare professionals at GRCC including medical oncologists, nurses, gynecologists and psychologists with long-term experience in $\mathrm{BC}$ and by patient advocacy groups. The final version was reviewed by the research team, tested on a small sample of volunteer patients, and modified according to their comments. The final questionnaire is available in the supplementary appendix and comprises 30 questions divided into 3 main sections: general information (10 questions) including age range, education, family composition, menopausal status, comorbidities, and co-medications; information on BC and treatments (5 questions) such as early or metastatic BC, treatments received and ongoing; and questions on women's SH (15 questions) including: current satisfaction with sexual life compared to sexual life before $\mathrm{BC}$ diagnosis, communication on $\mathrm{SH}$ with health-care professionals after the diagnosis of $\mathrm{BC}$, the nature of this communication, who initiated the communication and when, patients' preferences, and barriers on communication about $\mathrm{SH}$.

\section{PRIMARY AND SECONDARY OUTCOMES}

The primary outcome was the rate of women who received information from health professionals about $\mathrm{SH}$ at any time during their $\mathrm{BC}$ care, from diagnosis to follow-up. The secondary outcomes were (1) to describe the main characteristics of such communication on $\mathrm{SH},(2)$ to assess the perceived impact of breast cancer/its treatments on sexual satisfaction, and (3) to explore factors associated to women's satisfaction with $\mathrm{SH}$ and to communication on $\mathrm{SH}$ after $\mathrm{BC}$ diagnosis.

\section{STATISTICAL ANALYSIS}

Descriptive statistics were used to describe patients' characteristics (age range, education, family composition, menopausal status, comorbidities and co-medications), BC characteristics (stage and type of treatments), satisfaction with $\mathrm{SH}$ and communication on $\mathrm{SH}$. 
The primary outcome was computed as the proportion of women who received at least one communication on $\mathrm{SH}$ after the diagnosis of $\mathrm{BC}$.

Continuous variables were expressed using medians and ranges. Categorical variables were summarized using absolute count and percentages.

Current sexual satisfaction was compared retrospectively to the sexual satisfaction diagnosis and / or before treatment using a McNemar test.

We also explored the association between the single following variables: women's age range, tumour stage and ongoing treatment and the items: (1) women reported satisfaction with sexuality before BC diagnosis and at time of survey (2) perceived importance of addressing sexuality during BC follow-up.

Associations were tested using Kendall's correlation tests for ordinal variables, Cochran-Armitage trend tests, or Chi-square or Fisher's exact tests when appropriate.

As these latter analyses were exploratory, p-values were not corrected for test multiplicity so they should be interpreted with caution.

All analyses were performed using R (version 4.0.3) and the "tidyverse" packages $[37,38]$ with a significance level of $5 \%$ for 2 -sided tests.

\section{Results}

A total of 580 women were given the paper questionnaire, while 62 were invited to fill the questionnaire in digital form after their teleconsultation; 329/580 (57\%) and 19/62 (31\%) women filled the paper and online questionnaire respectively. After removing incomplete questionnaires $(n=25,7.5 \%)$ and overt refusals to participate in the study $(n=5,1.5 \%), 318$ questionnaires were assessable for our analysis (94\% in paper format and $6 \%$ in digital version; Fig. 1 ).

\section{PARTICIPANT CHARACTERISTICS}

Main participant characteristics are summarized in Table 1. Sixty-one percent of women were older than $50(n=194)$. Almost $80 \%$ were married/partnered $(n=253)$ and $86 \%(n=275)$ had at least one child. The majority $(n=166,52.2 \%)$ had a university-level academic education. Forty percent $(n=128)$ of women were postmenopausal before their diagnosis of $\mathrm{BC}$ and treatment initiation, $79 \%$ at the time of the survey. Sixty-five percent $(n=206)$ of women declared to have a localized BC. The majority of patients were currently receiving chemotherapy or hormone therapy $(n=83,26 \%$ and $n=118,37 \%$ respectively, Table 2$)$. The median time since the $\mathrm{BC}$ diagnosis was 3 years [range, 1-7]. 
Table 1

General clinical and socio-characteristics of the participants

\begin{tabular}{|c|c|c|c|}
\hline Participant characteristics & & $N=318$ & $\%$ \\
\hline \multirow[t]{6}{*}{ Age } & $<30$ years & 4 & 1.3 \\
\hline & $30-39$ years & 34 & 10.7 \\
\hline & $40-49$ years & 86 & 27.0 \\
\hline & $50-59$ years & 118 & 37.1 \\
\hline & $60-69$ years & 61 & 19.2 \\
\hline & $>70$ years & 15 & 4.7 \\
\hline \multirow[t]{3}{*}{ Marital status } & Partnered/Married & 253 & 79.6 \\
\hline & Median couple duration (years, [IQR]) & $21[14-30]$ & 20.4 \\
\hline & Single & 65 & \\
\hline \multirow[t]{2}{*}{ Child(ren) } & Yes & 275 & 86.5 \\
\hline & No & 43 & 13.5 \\
\hline \multirow[t]{4}{*}{ Education level } & Primary or High school & 57 & 17.9 \\
\hline & College & 85 & 26.7 \\
\hline & Higher than College & 166 & 52.2 \\
\hline & Unknown & 10 & 3.1 \\
\hline \multirow[t]{2}{*}{ Menopausal status at $\mathrm{BC}$ diagnosis } & Post-menopausal & 128 & 40.2 \\
\hline & Pre menopausal & 190 & 59.8 \\
\hline \multirow[t]{3}{*}{ Current menopausal status } & Post-menopausal & 250 & 78.6 \\
\hline & Amenorrhea for less than 1 year & 34 & 10.7 \\
\hline & Regular menstrual cycles & 34 & 10.7 \\
\hline \multirow[t]{2}{*}{ Other chronic pathology } & Yes & 72 & 22.6 \\
\hline & No & 246 & 77.4 \\
\hline \multirow[t]{2}{*}{ Other chronic treatment(s) } & Yes & 54 & 17.0 \\
\hline & No & 264 & 83.0 \\
\hline $\mathrm{BC}=$ breast cancer & & & \\
\hline
\end{tabular}


Table 2

Cancer stage and treatment characteristics

\begin{tabular}{|c|c|c|c|}
\hline \multicolumn{2}{|c|}{ Cancer stage and treatment characteristics } & \multirow{2}{*}{$\begin{array}{l}\mathbf{N}=\mathbf{3 1 8} \\
3[1-7]\end{array}$} & \multirow{2}{*}{$\begin{array}{l}\% \\
17.9\end{array}$} \\
\hline Time from $\mathrm{BC}$ diagnosis & Median (years, [IQR]) & & \\
\hline & $<1$ year & 57 & 49.7 \\
\hline & $1-5$ years & 158 & 32.4 \\
\hline & $>5$ years & 103 & \\
\hline \multirow[t]{3}{*}{ BC stage } & Localized & 206 & 64.8 \\
\hline & Metastatic & 94 & 29.6 \\
\hline & Unknown & 18 & 5.7 \\
\hline \multirow[t]{8}{*}{ Current treatment } & Before starting any treatment & 2 & 0.6 \\
\hline & After surgery and before any other treatment & 7 & 2.2 \\
\hline & During chemotherapy & 83 & 26.1 \\
\hline & During radiotherapy & 12 & 3.8 \\
\hline & During hormone therapy & 118 & 37.1 \\
\hline & Other & 23 & 7.2 \\
\hline & After any treatment & 67 & 21.0 \\
\hline & Unknown & 6 & 1.9 \\
\hline \multirow[t]{9}{*}{ Prior treatments } & Surgery: & 279 & 87.7 \\
\hline & Lumpectomy & 123 & 38.7 \\
\hline & Mastectomy with immediate or delayed reconstruction & 106 & 33.3 \\
\hline & Mastectomy without reconstruction & 50 & 15.7 \\
\hline & Chemotherapy & 269 & 84.6 \\
\hline & Radiotherapy & 227 & 71.4 \\
\hline & Hormone therapy & 187 & 58.8 \\
\hline & Other & 53 & 16.7 \\
\hline & Unknown & 1 & 0.3 \\
\hline
\end{tabular}

COMMUNICATION ON SEXUAL HEALTH AFTER BREAST CANCER DIAGNOSIS 
Overall, $65 \%(n=207)$ of women reported that they did not have any conversation with any health care provider regarding their SH (Fig. 2 and supplementary Table 1S). Fourteen percent of those who had a discussion with a health care professional $(n=45 / 318)$ had brought up the topic on their own.

Two-thirds of women $(n=218,69 \%)$ reported that they considered important to discuss sexual issues during the visits planned for their BC treatment, and for $31 \%(n=100)$ of them, professionals, preferably oncologists or gynecologists, should have initiated the discussion on the impact of BC diagnosis and treatment on SH. When sexual consequences were discussed, it was mainly in terms of adverse effects that treatments could have on sexuality: the health-care provider informed the patient of their possible occurrence $(n=32)$ or asked if the patient had noted such adverse effects $(n=39)$. Sexual well-being was directly addressed in only $4.1 \%(n=13)$ of cases (Table $1 S)$.

When they were asked the most appropriate time for such communication, $45 \%(n=145)$ of women replied "along the whole care pathway". The majority also would have liked to discuss their sexual concerns in the presence of their partner $(n=277,87 \%)$. Participants reported that their preferred physician for such discussion was their oncologist $(n=161,51 \%)$, their gynecologist $(n=129,41 \%)$ or a sex therapist $(n=81,26 \%)$. Finally, the majority of women wished to discuss sexual consequences of BC in an in-person consultation $(n=218 ; 69 \%)$ or, to receive information through a specific leaflet or website $(n=117,37 \%$ and $n=49,15 \%$ respectively).

\section{SEXUAL HEALTH AFTER BREAST CANCER DIAGNOSIS}

Women were questioned a posteriorion their satisfaction with their sexuality before the diagnosis and / or treatment of BC and then at the time of the survey (Supplementary Table 1). The majority of women reported they were satisfied with their sexuality before the BC diagnosis (166, 52\%; Fig. 3 ) or even very satisfied $(98,31 \%)$. At the time of survey completion, satisfaction with sexual life had significantly decreased $(p<0.0001)$ and only $30 \%$ of women stated they were satisfied or very satisfied with their sexuality $(76,24 \%$ and $18,6 \%$ respectively). Two-thirds of women $(n=213,67 \%)$ perceived a negative impact of cancer and its treatments on their sexuality (supplementary Table 1), mainly due to increased vaginal dryness $(n=134,42 \%)$, decreased desire $(n=121,38 \%)$ and a change in body image $(n=86$, $26 \%$ ). For $28 \%(n=90 ; 24 \%$ single and $76 \%$ partnered) of women, sexuality was not a priority at the time of the study. Interestingly, almost a fifth of them reported a positive impact of cancer on their sexuality (n $=60,19 \%)$, mostly in virtue of an improved communication with their partner $(26,8 \%)$.

\section{EXPLORATORY FACTORS ASSOCIATED TO SEXUAL HEALTH SATISFACTION AND COMMUNICATION ON SEXUAL HEALTH}

We also evaluated the association between age range, tumor stage and ongoing treatment (especially chemotherapy and endocrine therapy versus other treatments) with current and pre-diagnosis satisfaction with sexuality and communication on $\mathrm{SH}$. 
Age was not associated with satisfaction with sexuality before BC $(p=0.22)$ or at the time of survey $(p=$ 0.49). Communication on $\mathrm{SH}$ was of less importance to women with older age ( $p=0.03)$, however, $64 \%$ of the patients in the oldest group (> 70 years) still considered this topic important (supplementary Fig. 1S).

Tumor stage was significantly associated with satisfaction with current sexuality, a lower satisfaction being more frequent in patients with metastatic tumors ( $p=0.005$; Fig. $2 S$ ).

Finally, ongoing treatment was not significantly associated with current satisfaction with sexuality $(p=$ 0.16; Fig. 3S).

\section{Discussion}

Although SH is an important dimension of quality of life and BC diagnosis and therapies are associated with a high risk of developing transient or permanent sexual disruptions, very few women obtain information or have access to an appropriate counseling focused on sexual issues after their BC diagnosis.

Our study confirms the lack of communication between patients and health-care professionals on $\mathrm{SH}$ in women with BC. Our results are consistent with the data that can be found in scientific literature with nearly 4 out of 5 women not having received information from health professionals $[26,39]$.

Furthermore, we found a significant deterioration in women's self-rated satisfaction with the quality of their sexual life compared to their pre-diagnosis satisfaction levels [25]. It is also interesting to note that almost one in five women was not satisfied with her SH before BC was diagnosed. These figures are consistent with those carried out by Lammerink et al in 2017 on 521 sexually active and healthy women in the Dutch general population: more than a quarter of which had a sexual dysfunction [40].

Women preferred to be provided with information on $\mathrm{SH}$ throughout their treatment plan, starting as soon as the diagnosis, as recommended by the American Society of Clinical Oncology (ASCO, [41]) and by national societies, such as the French Association of Supportive Oncological Care (AFSOS, [24]). Participation of the partner in the discussion on SH was essential for most of participants [20]. Despite the lack of training of oncologists in $\mathrm{SH}$, they were the preferred interlocutors for women, certainly due to the relationship of trust that can develop throughout the whole BC care journey [39]. Thus, oncologists are expected to initiate the discussion $[25,32]$ on the impact of $\mathrm{BC}$ on $\mathrm{SH}$, preferably during in-person consultations, with a clear and inclusive language that make the women and their partners comfortable enough to raise specific questions on this topic.

In our exploratory analyses, as already shown in other studies [33], age did not affect sexual satisfaction, although SH seemed to be a little less essential to discuss for older women.

As expected, metastatic status appeared to be more associated with poorer quality of sexual life [28], but $\mathrm{SH}$ issues was as important to discuss as for women with early BC. 
Although analysis of sexual satisfaction according to oncological treatment was only exploratory, we did not find any significant difference among patients receiving endocrine therapy and chemotherapy. This differs from the study of Ganz et al [10] in which a greater deterioration of sexual functioning was associated with chemotherapy. It is likely that in our study, the lack of difference is determined by the prevalent use of aromatase-inhibitors +/- ovarian suppression that exacerbate menopausal symptoms more than tamoxifene [42].

Better management of SH has the potential to increase adherence to treatments [43,44], to reduce certain symptoms such as anxiety or depression associated with BC therapy and to improve communication within the couple and in the family $[18,45-47]$, with a significant positive effect on the daily well-being.

The first step is to inform the patients about the consequences of the disease and its treatments on SH and provide advice on the possible remedies for the woman and the couple. Regardless of age [48], disease curability [32] and phase of treatment [26], early and regular support on SH must be offered to all women facing BC diagnosis and treatments, in full respect of women's sexual preferences, cultural diversities and feelings [49].

To this purpose, health professionals should receive adequate training to discuss sexual disorders with their patients and to provide them with appropriate counseling [50].

Our study has some limitations. First, because we aimed to draw an overall picture on sexual health communication in women with breast cancer, we allowed the inclusion of women with all breast cancer stages and presenting with a wide range of clinical conditions. We acknowledge that the population heterogeneity hampers the possibility of drawing solid conclusions from the information collected through the survey. Furthermore, it is likely that most of the women with poorer clinical condition did not reply to the survey so biasing our results. However, our findings underline that sexual issues require further evaluation also in patients with advanced breast cancer. Secondly, this study was conducted in a single large cancer center to which are frequently referred patients with more complex or advanced BC or at younger age, who may require a highly specialized multidisciplinary approach. It is likely that the survey participants are not sufficiently representative of the overall population with BC. Indeed, since the majority of women in our sample are highly educated, it is likely that many of them voluntarily chose a highly specialized center. However, in our study, women were coming from various geographic areas, so making our results more generalizable. Furthermore, the age structure of our sample is fairly representative of that of women with $B C$ in France [51]. Thirdly, to ensure the provision of total anonymity to the participants, all data concerning their disease and treatments and overall clinical conditions, were self-reported. We acknowledge that due to self-reporting, many clinical data may be inaccurate and incomplete. However, because of the highly sensitive nature of the survey topic, we preferred to sacrifice clinical data accuracy and rely on self-reported data with the purpose of avoiding patient embarrassment. Fourthly, information regarding sexual health before breast cancer were collected retrospectively, so a recall bias has to be considered in their interpretation. It is likely that patients tended to describe their sexual life as more satisfying and fulfilling prior to breast cancer diagnosis and treatment. Fifth, because 
our study was based on the response to a questionnaire that was collected only once over the BC care pathway, we were not able to assess the longitudinal evolution of sexual quality of life over treatment and follow-up. Then, we cannot use a validated questionnaire, as to our knowledge a questionnaire validated to evaluate communication on $\mathrm{SH}$ in patients with cancer does not exist. However, our questionnaire was created after a large literature review, coordinated and reviewed by a multidisciplinary team. Finally, we were not able to precisely assess the rate of refusal to participate as multiple channels were used to address women with BC. Indeed, we expected a higher recruitment. It was not reached probably for multiple reasons, such as the heavy emotional context faced by patients consulting for BC, the content of the survey as well as the major changes in outpatient visits due to the Covid-19 pandemic. This lower recruitment undermines the BEROSE study's capacity to identify factors associated to SH and likelihood of communicating on this topic.

In conclusion, $\mathrm{SH}$, although recognized as central component of quality of life remains in general - and in particular in the oncological field - a theme that is rarely mentioned. Our study clearly underlined that all patients, regardless of age, $\mathrm{BC}$ stages and ongoing treatment, are concerned about the possible impact of $B C$ treatments on sexual function and are interested in maintaining a good sex life [24, 41].

\section{Declarations}

\section{Acknowledgements:}

Thanks to R. Le Grand, AL. Gerard and J. Chassaing for their precious help in the realization of this study.

Funding (information that explains whether and by whom the research was supported): not applicable.

Conflicts of interest/Competing interests (include appropriate disclosures):

B. Pistilli: consulting fees from Puma Biotechnology, Novartis, Myriad Genetics, Pierre Fabre ; travel from Novartis, AstraZeneca, MSD Oncology, Pfizer ; Research fundings from Daiichi, Puma Biotechnology, Novartis, Merus, Pfizer, AstraZeneca. I. Vaz Luis: Honoraria from Amgen, Pfizer, Novartis. A. Di Meglio: Honoraria from ThermoFisher Scientific. The other co-authors declare no conflict of interest.

Availability of data and material (data transparency): all data generated and analyzed during this study are available from the corresponding author upon reasonable request.

Code availability (software application or custom code): not applicable.

Authors' contributions (optional: please review the submission guidelines from the journal whether statements are mandatory): not applicable.

Ethics approval (include appropriate approvals or waivers): this study has been approved on April 28, 2020 by a French Ethics Committee. 
Consent to participate (include appropriate statements): by completing the questionnaire, participants gave their consent. s this consistent with the French regulation of clinical trials ? Is this consistent with the French regulation of clinical trials ?Is this consistent with the French regulation of clinical trials?

Consent for publication (include appropriate statements): not available.

\section{References}

1. Street W (1930) Cancer Facts \& Figures 2020. American Cancer Society Breast Cancer Facts \& Figures 202076

2. (2018) GLOBOCAN (IARC): Population fact sheets, Europe, 2018 http://gco.iarc.fr/today/data/factsheets/populations/908-europe-fact-sheets.pdf

3. Siegel RL, Miller KD, Jemal A (2019) Cancer statistics, 2019. CA Cancer J Clin 69:7-34. https://doi.org/10.3322/caac.21551

4. Europe. In: The Cancer Atlas. http://canceratlas.cancer.org/F5S. Accessed 7 Nov 2020

5. Howard-Anderson J, Ganz PA, Bower JE, Stanton AL (2012) Quality of life, fertility concerns, and behavioral health outcomes in younger breast cancer survivors: a systematic review. J Natl Cancer Inst 104:386-405. https://doi.org/10.1093/jnci/djr541

6. Buković D, Fajdić J, Hrgović Z, et al (2005) Sexual dysfunction in breast cancer survivors. Onkologie 28:29-34. https://doi.org/10.1159/000082115

7. Panjari M, Bell RJ, Davis SR (2011) Sexual function after breast cancer. J Sex Med 8:294-302. https://doi.org/10.1111/j.1743-6109.2010.02034.x

8. Ussher JM, Perz J, Gilbert E (2013) Information needs associated with changes to sexual wellbeing after breast cancer. J Adv Nurs 69:327-337. https://doi.org/10.1111/j.1365-2648.2012.06010.x

9. Gilbert E, Emilee G, Ussher JM, Perz J (2010) Sexuality after breast cancer: a review. Maturitas 66:397-407. https://doi.org/10.1016/j.maturitas.2010.03.027

10. Ganz PA, Kwan L, Stanton AL, et al (2004) Quality of life at the end of primary treatment of breast cancer: first results from the moving beyond cancer randomized trial. J Natl Cancer Inst 96:376387. https://doi.org/10.1093/jnci/djh060

11. Fobair P, Stewart SL, Chang S, et al (2006) Body image and sexual problems in young women with breast cancer. Psychooncology 15:579-594. https://doi.org/10.1002/pon.991

12. Arora NK, Gustafson DH, Hawkins RP, et al (2001) Impact of surgery and chemotherapy on the quality of life of younger women with breast carcinoma: a prospective study. Cancer 92:1288-1298. 
https://doi.org/10.1002/1097-0142(20010901)92:5<1288::aid-cncr1450>3.0.co;2-e

13. Ferreira AR, Di Meglio A, Pistilli B, et al (2019) Differential impact of endocrine therapy and chemotherapy on quality of life of breast cancer survivors: a prospective patient-reported outcomes analysis. Ann Oncol 30:1784-1795. https://doi.org/10.1093/annonc/mdz298

14. Loaring JM, Larkin M, Shaw R, Flowers $P$ (2015) Renegotiating sexual intimacy in the context of altered embodiment: the experiences of women with breast cancer and their male partners following mastectomy and reconstruction. Health Psychol 34:426-436. https://doi.org/10.1037/hea0000195

15. Barton DL, Ganz PA (2015) Symptoms: Menopause, Infertility, and Sexual Health. Adv Exp Med Biol 862:115-141. https://doi.org/10.1007/978-3-319-16366-6_9

16. Sadovsky R, Basson R, Krychman M, et al (2010) Cancer and sexual problems. J Sex Med 7:349-373. https://doi.org/10.1111/j.1743-6109.2009.01620.x

17. Dumas A, Vaz Luis I, Bovagnet T, et al (2020) Impact of Breast Cancer Treatment on Employment: Results of a Multicenter Prospective Cohort Study (CANTO). J Clin Oncol 38:734-743. https://doi.org/10.1200/JC0.19.01726

18. Kathleen A, Morgan D, Rebekah F (2010) Managing the unmet psychosocial and information needs of patients with cancer. Patient Intelligence 2:. https://doi.org/10.2147/PI.S9442

19. Bondil P, Habold D, Carnicelli D (2016) Cancer et sexualité : le couple, un déterminant trop souvent négligé. Sexologies 25:61-68. https://doi.org/10.1016/j.sexol.2016.03.002

20. Hawkins Y, Ussher J, Gilbert E, et al (2009) Changes in sexuality and intimacy after the diagnosis and treatment of cancer: the experience of partners in a sexual relationship with a person with cancer. Cancer Nurs 32:271-280. https://doi.org/10.1097/NCC.0b013e31819b5a93

21. Milbury K, Badr H (2013) Sexual problems, communication patterns, and depressive symptoms in couples coping with metastatic breast cancer. Psychooncology 22:814-822. https://doi.org/10.1002/pon.3079

22. S.Dolbeault1, 2, 3, C.Flahault1, 4, A.Brédart1, 4 (2009) Approche psycho-oncologique des difficultés intimes et sexuelles des patientes atteintes de cancer féminin et de leur conjoint

23. Delgado-Guay M, Parsons HA, Li Z, et al (2009) Symptom distress in advanced cancer patients with anxiety and depression in the palliative care setting. Support Care Cancer 17:573-579. https://doi.org/10.1007/s00520-008-0529-7

24. BONDIL P, HABOLD D (2017) Cancer, vie intime et santé sexuelle - AFSOS 
25. Almont T, Delannes M, Ducassou A, et al (2017) Sexual Quality of Life and Needs for Sexology Care of Cancer Patients Admitted for Radiotherapy: A 3-Month Cross-Sectional Study in a Regional Comprehensive Reference Cancer Center. J Sex Med 14:566-576.

https://doi.org/10.1016/j.jsxm.2017.02.013

26. Reese JB, Sorice K, Lepore SJ, et al (2019) Patient-clinician communication about sexual health in breast cancer: A mixed-methods analysis of clinic dialogue. Patient Educ Couns 102:436-442. https://doi.org/10.1016/j.pec.2018.10.003

27. Den Ouden MEM, Pelgrum-Keurhorst MN, Uitdehaag MJ, De Vocht HM (2019) Intimacy and sexuality in women with breast cancer: professional guidance needed. Breast Cancer 26:326-332. https://doi.org/10.1007/s12282-018-0927-8

28. Leung MW, Goldfarb S, Dizon DS (2016) Communication About Sexuality in Advanced Illness Aligns With a Palliative Care Approach to Patient-Centered Care. Curr Oncol Rep 18:11. https://doi.org/10.1007/s11912-015-0497-2

29. Rouanne M, Massard C, Hollebecque A, et al (2013) Evaluation of sexuality, health-related quality-of-life and depression in advanced cancer patients: a prospective study in a Phase I clinical trial unit of predominantly targeted anticancer drugs. Eur $\mathrm{J}$ Cancer 49:431-438. https://doi.org/10.1016/j.ejca.2012.08.008

30. P. Bondil, D. Habol (2012) Cancer et sexualité: les médecins ne doivent plus faire l'impasse

31. Flynn KE, Reese JB, Jeffery DD, et al (2012) Patient experiences with communication about sex during and after treatment for cancer. Psychooncology 21:594-601. https://doi.org/10.1002/pon.1947

32. Wang K, Ariello K, Choi M, et al (2018) Sexual healthcare for cancer patients receiving palliative care: a narrative review. Ann Palliat Med 7:256-264. https://doi.org/10.21037/apm.2017.10.05

33. Reese JB, Beach MC, Smith KC, et al (2017) Effective patient-provider communication about sexual concerns in breast cancer: a qualitative study. Support Care Cancer 25:3199-3207. https://doi.org/10.1007/s00520-017-3729-1

34. Reese JB, Sorice K, Beach MC, et al (2017) Patient-provider communication about sexual concerns in cancer: a systematic review. J Cancer Surviv 11:175-188. https://doi.org/10.1007/s11764016-0577-9

35. Wiggins DL, Wood R, Granai CO, Dizon DS (2007) Sex, intimacy, and the gynecologic oncologists: survey results of the New England Association of Gynecologic Oncologists (NEAGO). J Psychosoc Oncol 25:61-70. https://doi.org/10.1300/J077v25n04_04

36. Jonsdottir JI, Zoëga S, Saevarsdottir T, et al (2016) Changes in attitudes, practices and barriers among oncology health care professionals regarding sexual health care: Outcomes from a 2-year 
educational intervention at a University Hospital. Eur J Oncol Nurs 21:24-30.

https://doi.org/10.1016/j.ejon.2015.12.004

37. R Core Team. R: A Language and Environment for Statistical Computing [Internet]. Vienna, Austria: R Foundation for Statistical Computing; 2020. https://www.r-project.org/. Accessed 22 Dec 2020

38. Wickham H, Averick M, Bryan J, Chang W, McGowan LD, François R, et al. Welcome to the tidyverse. J Open Source Softw. 2019;4(43):1686.

39. Sporn NJ, Smith KB, Pirl WF, et al (2015) Sexual health communication between cancer survivors and providers: how frequently does it occur and which providers are preferred? Psychooncology 24:1167-1173. https://doi.org/10.1002/pon.3736

40. Lammerink EAG, de Bock GH, Pascal A, et al (2017) A Survey of Female Sexual Functioning in the General Dutch Population. J Sex Med 14:937-949. https://doi.org/10.1016/j.jsxm.2017.04.676

41. Carter J, Lacchetti C, Andersen BL, et al (2018) Interventions to Address Sexual Problems in People With Cancer: American Society of Clinical Oncology Clinical Practice Guideline Adaptation of Cancer Care Ontario Guideline. J Clin Oncol 36:492-511. https://doi.org/10.1200/JC0.2017.75.8995

42. A planned comparison of menopausal symptoms during the first year in 1,000 patients receiving either exemestane or tamoxifen in a double-blind adjuvant hormonal study | Journal of Clinical Oncology. https://ascopubs.org/doi/abs/10.1200/jco.2004.22.90140.516. Accessed 7 Jun 2021

43. Pistilli B, Paci A, Ferreira A, Meglio A, Poinsignon V, Bardet A, Menvielle G, Dumas A, Pinto S, Dauchy S, Fasse L, Cottu P, Lerebours F, Coutant C, Lesur A, Tredan O, Soulie P, Vanlemmens L, Jouannaud C, Levy C, Everhard S, Arveux P, Martin AL, Dima A, Lin, Ann H. Partridge A, Delaloge S, Michiels S, André F, Vaz-Luis I. (2020) Serum detection of non-adherence to adjuvant tamoxifen and breast cancer recurrence risk. JCO in press

44. Villarreal-Garza C, López-Martínez EA, Martínez-Cannon BA, et al (2019) Medical and information needs among young women with breast cancer in Mexico. Eur J Cancer Care (Engl) 28:e13040. https://doi.org/10.1111/ecc.13040

45. Kim J-H, Yang Y, Hwang E-S (2015) The Effectiveness of Psychoeducational Interventions Focused on Sexuality in Cancer. Cancer Nurs 38:E32-42.

https://doi.org/10.1097/NCC.0000000000000212

46. Chow KM, Chan JCY, Choi KKC, Chan CWH (2016) A Review of Psychoeducational Interventions to Improve Sexual Functioning, Quality of Life, and Psychological Outcomes in Gynecological Cancer Patients. Cancer Nurs 39:20-31. https://doi.org/10.1097/NCC.0000000000000234

47. Reinhart R, D'Alimonte L, Osmar K, et al (2014) Educating our patients collaboratively: a novel interprofessional approach. J Cancer Educ 29:382-388. https://doi.org/10.1007/s13187-014-0623-0 
48. Schover LR, van der Kaaij M, van Dorst E, et al (2014) Sexual dysfunction and infertility as late effects of cancer treatment. EJC Suppl 12:41-53. https://doi.org/10.1016/j.ejcsup.2014.03.004

49. Katz A (2011) Breast cancer and women's sexuality. Am J Nurs 111:63-67.

https://doi.org/10.1097/01.NAJ.0000396560.09620.19

50. Faghani S, Ghaffari F (2016) Effects of Sexual Rehabilitation Using the PLISSIT Model on Quality of Sexual Life and Sexual Functioning in Post-Mastectomy Breast Cancer Survivors. Asian Pac J Cancer Prev 17:4845-4851. https://doi.org/10.22034/APJCP.2016.17.11.4845

51. InCa (2016) Les cancers en France. https://www.ecancer.fr/ressources/cancers_en_france/\#page $=65$

\section{Figures}

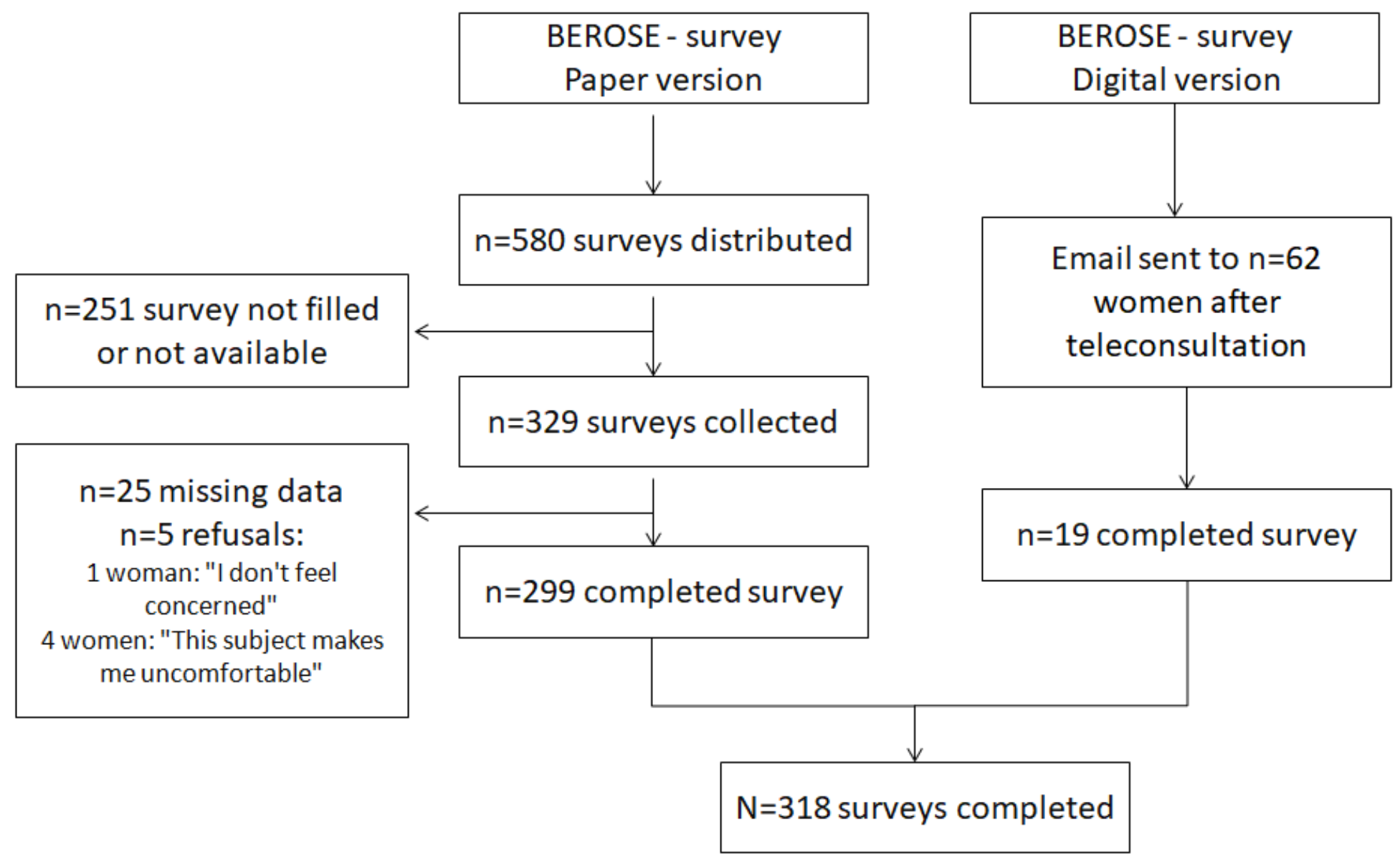

Figure 1

Consort diagram 
Yes, by my gynecologist or my general practitioner

Yes, by a physician . or nurse at GRCC

Yes, by myself-

No-
$9.7 \%$

$11.0 \%$

$14.2 \%$
$65.1 \%$

$75^{\prime} \%$

$100 \%$

\section{Figure 2}

Distribution of answers to the question 22 : "The topic of sexuality was addressed in the consultation" in survey participants. Abbreviation: GRCC = Gustave Roussy Cancer Center

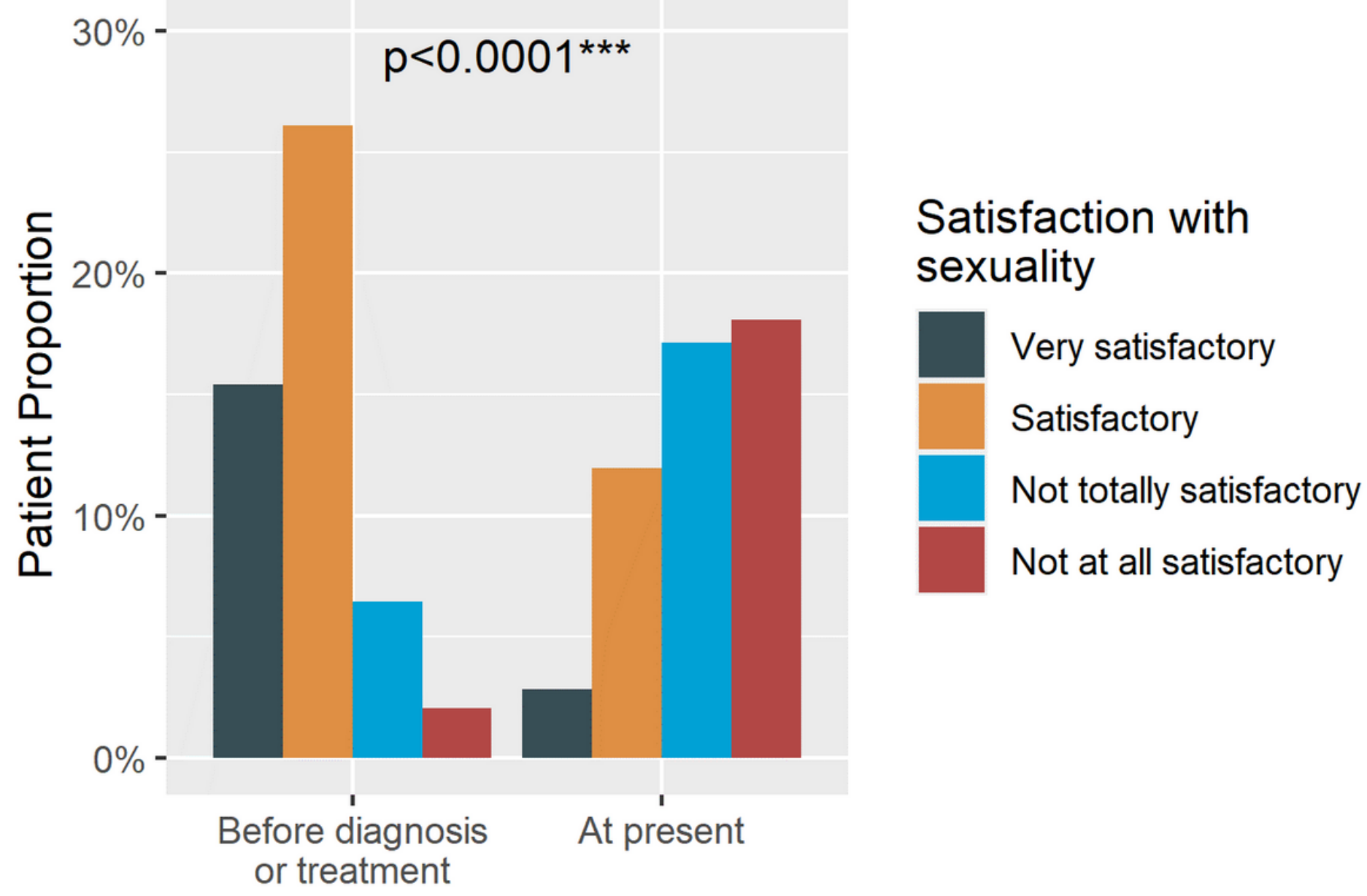




\section{Figure 3}

Retrospective self-reported satisfaction with sexuality before BC diagnosis and/or treatment and at present a Abbreviation: $\mathrm{BC}=$ Breast Cancer a p-value was computed using a McNemar test for paired values. 